\title{
Game Theory Analysis on the Incentive Mechanism of Technology Innovation Diffusion in the High-tech Zone
}

\author{
Yang Guo-zhong \\ Business School, Central South University, Changsha, China
}

Email address:

y5735@126.com

To cite this article:

Yang Guo-zhong. Game Theory Analysis on the Incentive Mechanism of Technology Innovation Diffusion in the High-tech Zone. Advances in Sciences and Humanities. Vol. 3, No. 6, 2017, pp. 82-86. doi: 10.11648/j.ash.20170306.12

Received: February 28, 2017; Accepted: April 26, 2017; Published: October 31, 2017

\begin{abstract}
By constructing and analyzing the incentive model of technology innovation diffusion in high-tech zone, it is found out that the traditional incentive mechanism will lead technology innovation diffusion into "Prisoner's Dilemma", and asymmetrical information's merely direct incentive to the technology diffusion will result in incentive distortion. Thus, the improved incentive mechanism model based on pooling of interests in high-tech zone is brought forward, and the relevant factors influencing the level of innovation diffusion are obtained. There is a further conclusion that the design of incentive contract and incentive coefficient in high-tech zone should accord to the different innovation ability and the marginal income between the enterprises during diffusion respectively.
\end{abstract}

Keywords: High-tech Zone, Innovation Diffusion, Incentive Mechanism

\section{Introduction}

With the development trend of economic globalization, in order to improve the international competitiveness, the development of high-tech industries with the high technical content, high value-added and high competitiveness is highly valued by many countries and regions, especially those developed ones. Therefore, the establishment of high-tech zones is becoming the primary mode of high-tech industries' development. During the research on high-tech development zones, it is found that some high-tech industry clusters with strong competitiveness (such as Silicon Valley in US, Cambridge in UK, Tsukuba in Japan, Hsinchu in Taiwan) develop healthily and maintain a strong vitality because of their innovation ability [1]. Obtaining innovation overflows from peer or relative enterprises is the main motivation for high-tech enterprises to gather. The effect of innovation spillovers can increase accumulation of knowledge and creation of new technologies in the cluster, and it is the ultimate cause for high-tech industrial cluster to improve their innovation ability and competitiveness [2-3].

Since the plan of high-tech industry development--Torch Program began in China in 1988, there is already 150 national high-tech zones granted by the State Council by 2016. However, the number of high-tech zones those have an impact both home and abroad is quite limited in China. This phenomenon is caused by various reasons, of which the most important one is that the management of the zone often merely values incentive to technology innovation while ignores the importance of incentive to technology innovation diffusion. So far, research results on technology innovation diffusion by game theory are mainly reflected in the timing analysis of the diffusion [4], the spillover effects of the diffusion [5-10], the role of firm size during the diffusion [11-12], the price of the new product in the diffusion of technological innovation and so on [13]. By constructing a static game model, taking the management as principal and all the enterprises in the zone as agent, this paper discusses the incentive mechanism step by step, and tries to establish a more suitable incentive mechanism model to the innovation diffusion in high-tech zone.

\section{Analysis of the Existing Incentive Mechanism to the Diffusion}

\subsection{The Prisoner's Dilemma Under the Incentive Mechanism to the Diffusion in High-Tech Zone}

In the early stages of the high-tech zone, management tends to focus on encouraging the innovation behavior of the 
enterprises. This kind of incentive mechanism can stimulate the enterprises' subjective initiative to accelerate their own technology innovation to some extent, but it will also induce fierce competition between enterprises for the limited incentive compensation from the management of the zone, which will lead the enterprises in the zone into prisoner's dilemma during technology innovation diffusion.

In order to simplify the problem, the following basic hypotheses are made firstly:

Hypothesis 1: There are only two enterprises in the zone, namely Enterprise $i$ and Enterprise $j$. Both are rationally expecting profit maximization.

Hypothesis 2: Enterprise $i$ and Enterprise $j$ independently choose their own output level. Each enterprise's marginal contribution to the economic output of the zone depends on the innovation level of the other enterprise. Suppose the output of Enterprise $i$ is affected by two kinds of innovation: its own innovation level $L i$ and the degree of diffusion from Enterprise $j$ to Enterprise $i S_{j}$; the same situation to Enterprise $j$. There is a synergistic effect in the bidirectional innovation diffusion. The revenue function of Enterprise $i$ is $R_{i}=L_{i}+u S_{j}+\delta_{i}$, and $u$ stands for the marginal revenue of the innovation diffusion, which reflects the interdependence between both enterprises in their contribution to the economic output of the zone. $\delta_{i}$ stands for the external random disturbance to Enterprise $i$, and $\delta_{i}$ obeys normal distribution with mean 0 and variance $\sigma_{i}{ }^{2}$. In a similar way, the revenue function of Enterprise $j$ is

$$
R_{j}=L_{j}+u S_{i}+\delta_{j} .
$$

Hypothesis 3: Based on that the cost function of the agent in the principal-agent model can be simplified [14], suppose the marginal cost coefficients of enterprises choosing to innovate on its own or choosing the innovation diffusion are both the constant $e_{i}$. The cost function will be $c_{i}=e_{i}\left(L \mathrm{i}^{2}+S i^{2}\right) / 2$. Namely, the larger of $e_{i}$, the more obvious of the negative effect to Enterprise $i$ from the innovation $\mathrm{Li}$ or $\mathrm{Si} . e_{i}$ stands for the level of innovation. Namely, the larger of $e_{i}$, the lower of the innovation level of the enterprise. In the similar way, there is also $c_{j}=e_{j}\left(L j^{2}+S j^{2}\right) / 2$.

Hypothesis 4: the revenue of Enterprise $i$ consists of the limited incentive compensation from the management of the zone $d$ and the production capacity $\beta R . \beta \in(0,1]$ stands for the output rate of one single enterprise. Namely, with output of the enterprise adding one unit, the revenue of enterprise will add $\beta$ unit. The linear incentive contract offered to the agent by the mandatory is $\pi_{i}=d+\beta R i$, $\pi_{j=d+\beta R j}$.

Hypothesis 5: the enterprises in the zone are neutral risk-averter and the profit function is

$$
\omega_{i}=\pi_{i}-c_{i}=d+\beta\left(L \mathrm{i}+\mathrm{u} S j+\delta_{i}\right)-e_{i}\left(L i^{2}+S i^{2}\right) / 2
$$

To maximize profits, the optimal strategy of Enterprise $i$ is $L i{ }^{*} S_{i}{ }^{*} \in \max \omega_{i}$. Let $\partial \omega_{i} / \partial L_{i}=\partial \omega_{i} / \partial S_{i}=0$, then the optimal strategy is $L_{i}{ }^{*}=\beta / e_{i}, S_{i}{ }^{*}=0$. In a similar way, the optimal strategy of Enterprise $j$ is $L_{j}{ }^{*}=\beta / e_{j}, S_{j}{ }^{*}=0$. Namely, the maximum expected profits of Enterprise $i, j$ are:

$$
\begin{aligned}
& \max E \omega_{i}=d+\beta^{2} / 2 e_{i}, \\
& \max E \omega_{j}=d+\beta^{2} / 2 e_{j}
\end{aligned}
$$

Right now, under the existing incentive mechanism the optimal strategy of enterprises in the zone is not diffusion. When the incentive compensation from the zone is limited, the revenue of enterprises grows with the improvement of their productivity level $\beta$. With complete information under static game between enterprises, no matter whether the other one

\begin{tabular}{|c|c|}
\hline & Enterprise $i$ \\
\hline 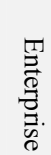 & 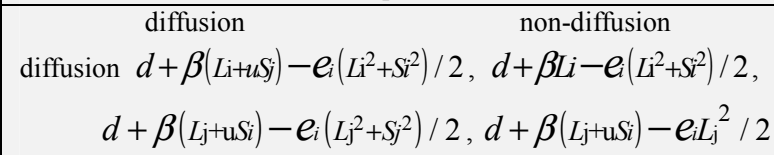 \\
\hline${ }^{j}$ & 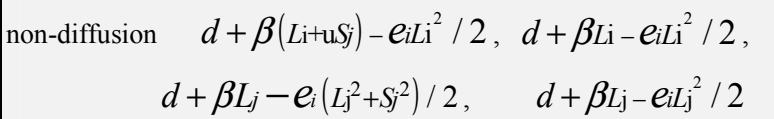 \\
\hline
\end{tabular}
chooses diffusion or not, Enterprise $i$ will pay an extra cost $e_{i} S_{i}^{2} / 2$, which will lower its profit (Table 1).

Table 1. Revenue matrix of enterprises under existing incentives.

So the non-diffusion becomes the best strategy to Enterprise $i$; similarly, the optimal strategy to Enterprise $j$ is non-diffusion as well. (non-diffusion, non-diffusion) is only pure strategy Nash equilibrium in the game model. Even there exists the synergistic effect in the innovation diffusion, the conflict between individual rationality and collective rationality will lead the enterprises into "prisoner's dilemma" and impede the mutual transfer of technology innovation.

\subsection{Incentive Distortion During Technology Innovation Diffusion in High-tech Zone}

Follow the basic assumptions $1 \sim 3$ and the companies are neutral risk averse, but there adds an incentive to the supplier who chooses to diffuse its new technology in the contract designed by the principal. The modified revenue function is $\pi_{i}=d+\beta R i+\lambda \alpha S_{i} \quad . \quad \beta \in[0,1) \quad$ is enterprise's own production levels, $\lambda \in(0,1]$ is the incentive coefficient for enterprise's behavior of technology innovation diffusion, and $\alpha \in(0,1]$ is the measurable degree of technology innovation diffusion effect by the management of the zone. Thus, the enterprise's profit function is

$$
\omega_{i}=\pi_{i}-c_{i}=d+\beta(L \mathrm{i}+\mathrm{u} S j+\delta i)+\lambda \alpha S i-e_{i}\left(L \mathrm{i}^{2}+S i^{2}\right) / 2
$$

Driven by its pursuit of profit maximization, the optimal 
strategy for Enterprise $i$ is $L_{i}{ }^{*} S_{i}{ }^{*} \in \max \omega_{i}$. Let $\partial \omega_{i} / \partial L_{i}=\partial \omega_{i} / \partial S_{i}=0$, then, $L_{i}{ }^{*}=\beta / e_{i}, S_{i}{ }^{*}=\eta \alpha / e_{i}$. Similarly, the optimal strategy for Enterprise $j$ is $L_{j}{ }^{*}=\beta / e_{j}, S_{j}{ }^{*}=\eta \alpha / e_{j}$. Because of $S_{i}{ }^{*}>0, S_{j}{ }^{*}>0$, under this incentive mechanism, technological innovation diffusion is the optimal strategy for all companies. The maximum expected profit is

$$
\begin{aligned}
& \max E \omega_{i}=d+\frac{\beta^{2}+\eta^{2} \alpha^{2}}{2 e_{i}}+\frac{\beta \eta u \alpha}{e_{j}} \\
& \max E \omega_{j}=d+\frac{\beta^{2}+\eta^{2} \alpha^{2}}{2 e_{j}}+\frac{\beta \eta u \alpha}{e_{i}}
\end{aligned}
$$

In addition, by the method described above it can deduce the maximum expected profit under the condition that one of the enterprises chooses to diffuse while the other one doesn't, and both enterprises choose not to diffuse. Then it comes to the benefit matrix of enterprises during technology innovation diffusion in the zone (Table 2).

Table 2. Revenue matrix of enterprises under incentives to behavior of

\begin{tabular}{|c|c|c|c|}
\hline \multirow{3}{*}{ 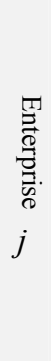 } & \multicolumn{3}{|c|}{ Enterprise $i$} \\
\hline & diffusion & $\begin{array}{c}\text { diffusion } \\
d+\frac{\beta^{2}+\eta^{2} \alpha^{2}}{2 e_{i}}+\frac{\beta \eta u \alpha}{e_{j}} \\
d+\frac{\beta^{2}+\eta^{2} \alpha^{2}}{2 e_{j}}+\frac{\beta \eta u \alpha}{e_{i}}\end{array}$ & $\begin{array}{l}\text { non-diffusion } \\
d+\frac{\beta^{2}+\eta^{2} \alpha^{2}}{2 e_{i}}, \\
d+\frac{\beta^{2}}{2 e_{j}}+\frac{\beta \eta u \alpha}{e_{i}}\end{array}$ \\
\hline & non-diffusion & $\begin{array}{c}d+\frac{\beta^{2}}{2 e_{i}}+\frac{\beta \eta u \alpha}{e_{j}} \\
d+\frac{\beta^{2}+\eta^{2} \alpha^{2}}{2 e_{j}}\end{array}$ & $\begin{array}{l}d+\frac{\beta^{2}}{2 e_{i}} \\
d+\frac{\beta^{2}}{2 e_{j}}\end{array}$ \\
\hline
\end{tabular}
technology innovation diffusion.

According to the revenue matrix, during the game between enterprises, whether the other one chooses to diffuse or not, the enterprise will get an extra net income $\frac{\eta^{2} \alpha^{2}}{2 e_{i}}$ to its profit if it chooses to diffuse. So diffusion becomes the optimal strategy to Enterprise $i$. Similarly, the optimal strategy to Enterprise $j$ is diffusion as well. Namely, (diffusion, diffusion) is the only pure strategy Nash equilibrium. It can be drawn that incentive to the supplier of the diffusion of new technologies can impel equilibrium of technology innovation diffusion between enterprises.

Because the measurable degree of technology diffusion effect $\alpha$ in the model $S{ }^{*}=\eta \alpha / e_{i}$ has a positive effect on the behavior of enterprise supplying the new technology, the more measurable the effect of technology innovate diffusion by the management of the zone, the more active of the innovation diffusion by the enterprises. However, the core of innovation is usually systematical and abstract. It is difficult for the management of the zone to make an appropriate incentive indicator. Therefore, information asymmetry between principal and agent will easily cause the incentive distortion [15], which will prevent diffusion achieving the expected effect.

\section{Improved Incentive Mechanism Model Based on Revenue Sharing in the Zone}

As the management of the zone, it is not just responsible to create a good business environment for enterprises in the zone, but also needs to promote the economic growth of the entire zone, expand its influence, attract more enterprises, then bring out a virtuous cycle by relying on the development of enterprises in the zone. Therefore, this paper tries to connect the interests of the zone and that of the enterprises, and promote the innovation diffusion by incentive mechanism of sharing revenue in the zone. This model balances the cost and the created value of innovation by the economic growth of the overall zone, and effectively avoids the incentive distortion problems caused by the non-testability of the degree of innovation diffusion.

\subsection{The Optimal Strategy of the Enterprises}

Follow the basic assumptions $1 \sim 3$ and the enterprises are neutral risk averse. The difference is that the incentive plan of sharing revenue is added to the linear incentive contract drafted by the management of the zone. Connect the revenue of Enterprise $i$ and Enterprise $j$ with that of the zone; it comes to the endogenous revenue structure $\pi_{i}=d+\beta R i+\eta(R i+R j) . \quad \beta \in[0,1)$ is the productivity of one single enterprise, and $\eta \in(0,1]$ is the incentive coefficient of sharing interests in the zone. Thus, the enterprise's profit function is

$$
\omega_{i}=\pi_{i}-c_{i}=d+(\beta+\eta)\left(L \mathrm{i}+\mathrm{u} S j+\delta_{i}\right)+\eta\left(L \mathrm{j}+\mathrm{u} S_{i}+\delta_{j}\right)-e_{i}\left(L \mathrm{i}^{2}+S i^{2}\right) / 2
$$

To maximize profit as the target, and based on the incentive contract $\boldsymbol{\pi}_{i}$, the enterprise chooses the optimal strategy $L{ }_{i}{ }^{*} S_{i}{ }^{*} \in \max \omega_{i}$. Let $\partial \omega_{i} / \partial L_{i}=\partial \omega_{i} / \partial S_{i}=0$, then, the optimal strategy to Enterprise $i$ is $L_{i}{ }^{*}=(\beta+\eta) / e_{i}$, $S_{i}{ }^{*}=u \eta / e_{i}$. Similarly, the optimal strategy to Enterprise $j$ is $L_{j}{ }^{*}=(\beta+\eta) / e_{j}, S_{j}{ }^{*}=u \eta / e_{j}$. Since $S_{i}{ }^{*}>0, S_{j}{ }^{*}>0$, under the new incentive mechanism the enterprises choose the diffusion as the optimal strategy. Respectively, their expected profits achieve maximum, which are:

$$
\begin{aligned}
& \max E \omega_{i}=d+\frac{(\beta+\eta)^{2}+u^{2} \eta^{2}}{2 e_{i}}+\frac{\eta(\beta+\eta)\left(u^{2}+1\right)}{e_{j}} \\
& \max E \omega_{j}=d+\frac{(\beta+\eta)^{2}+u^{2} \eta^{2}}{2 e_{j}}+\frac{\eta(\beta+\eta)\left(u^{2}+1\right)}{e_{i}}
\end{aligned}
$$

In a similar way, the revenue matrix of innovation diffusion is as following (Table 3). 
Table 3. The revenue matrix of the diffusion based on revenue sharing in the zone.

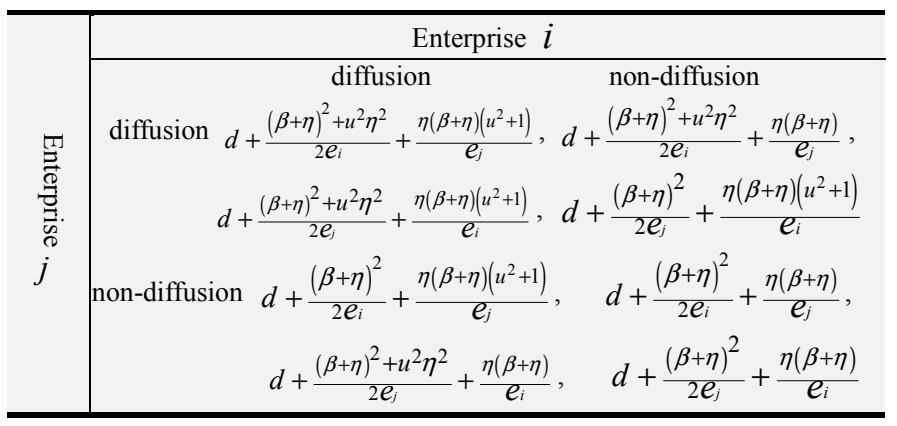

\subsection{The Optimal Strategy of the Managements}

The management of the zone as the principal, the aim of its incentive mechanism is to induce enterprises to select the most favorable behavior to the client from their own interests, and at the same time maximize its own interest. Under asymmetric information, in order to achieve this goal the management faces two constraints [16]: first, constraint of individual rationality, the expected profit that the enterprise gets from innovation diffusion must not be less than the maximum expected profit when they do not accept this mechanism; second, constraint of incentive compatibility, enterprises must actively choose innovation diffusion under this mechanism. As the principal, the optimal decision of the management is to select the appropriate contract of sharing revenue to maximize its own interests under the dual constraints of individual rationality and incentive compatibility. Suppose the principal is risk-neutral, and the optimization problem can be simplified as follows:

$$
\left\{\begin{array}{l}
d, \beta, \eta \in \max E U=\max \left\{L_{i}+L_{j}+u\left(S_{i}+S_{j}\right)-2 d-(\beta+2 \eta)\left[L_{i}+L_{j}+u\left(S_{i}+S_{j}\right)\right]\right\} \\
(I F 1) \omega_{i} \geq \pi_{i ;}^{*}(I F 2) \omega_{j} \geq \pi_{j} ;(I C 1) L_{i}, S_{i} \in \max \omega_{i ;}(I C 2) L_{j}, S_{j} \in \max \omega_{j ;}
\end{array}\right.
$$

$\boldsymbol{\pi}_{i}{ }^{*}, \boldsymbol{\pi}_{j}{ }^{*}$ is the minimum level of enterprise's income. If the expected profit is less than the level of guarantee income, the enterprise will not accept the contract. Under the condition of expecting the optimal profit, there is no reason for the principal to pay more to the enterprises, which means that the constraint of individual rationality works. Then, the above inequality is calculated to be:

$$
d=\pi_{i}^{*}-(\beta+\eta)(L i+u S j)-\eta(L j+u S i)+e_{i}\left(L i^{2}+S i^{2}\right) / 2
$$

Take the value of $\left(L i, S_{i}, L_{j}, S_{j}, d\right)$ into the principal objective function,

$$
E U=(1+\beta)\left(\frac{\beta+\eta}{e_{i}}+\frac{u^{2} \eta}{e_{j}}\right)+\eta\left(L_{j}+u S_{i}\right)+e_{i}\left(L_{i}{ }^{2}+S_{i}{ }^{2}\right)-\frac{(\beta+\eta)^{2}}{e_{i}}-\frac{u^{2} \eta^{2}}{e_{i}}-2 \pi_{i}^{*}
$$

Suppose $e_{j}=\rho e_{i}$, and let $\partial E U / \partial \beta=\partial E U / \partial \eta=0$,then,

$$
\left\{\begin{array}{c}
\beta=\frac{2(1+\rho)(1-\rho)\left(u^{4}-1\right)}{4 \rho\left(1+u^{2}\right)-\left(u^{2}-\rho u^{2}-\rho-1\right)^{2}} \\
\eta=\frac{(1+\rho)\left(3 u^{2}-\rho u^{2}-\rho+1\right)}{4 \rho\left(1+u^{2}\right)-\left(u^{2}-\rho u^{2}-\rho-1\right)^{2}}
\end{array}\right.
$$

So, when $\beta, \eta$ equal the value above, a Pareto optimal contract is achieved. In the equation, $u$ stands for the interdependence of innovation between enterprises. $\rho=e_{j} / e_{i}$ stands for the cost ratio of enterprise's innovation, reflecting the difference of innovation ability. Therefore, during the design of the incentive mechanism the management needs to take both factors into account. There is a extreme situation, when the $\rho=1$, thus, $\eta=1, \beta=0$ 。It means that when the enterprises are completely homogeneous, management should use the incentive contract which aims at all the enterprises in the zone rather than one single enterprise.

\section{The Conclusion}

By constructing and analyzing the static games model, it is found that under the existing incentive mechanism to innovation diffusion high-tech zones the prisoner's dilemma and incentive distortions exist. So, the incentive mechanism model of revenue sharing is put forward. In the improved model, the conclusions are as follows:

(1) According to $S i=u \eta / e_{i}$, the degree of the innovation diffusion is affected by the sharing incentive coefficient $\eta$, the marginal revenue of innovation diffusion $u$, and the marginal cost of innovation diffusion $e_{i}$. When $\partial S_{i} / \partial \eta>0$, improving the interests' relevance of the enterprises in the zone and the zone as a whole can promote the innovation diffusion. When $\partial S_{i} / \partial u>0$, with the marginal revenue of the innovation diffusion increasing, the innovation diffusion of the enterprises will be promoted. When $\partial S_{i} / \partial e_{i}<0$, with the cost of the innovation diffusion increasing, the degree of the innovation diffusion will get reduced.

(2) Because the integral interests of the zone indirectly affects the enterprises' revenue, according to the optimal strategy of the enterprise $L i=(\beta+\eta) / e_{i}$, improving the incentive coefficient of interests relation in the zone will promote the enterprises' initiative to innovation diffusion.

(3) In addition, the design of incentive coefficient in the contract should be according to the difference of the 
enterprises' innovation ability and the marginal revenue of the innovation diffusion between the enterprises.

\section{Acknowledgements}

Supported by Natural Science Foundation of Hunan Province (2017JJ2322) and Social Science Achievement Evaluation Committee of Hunan Province (XSP17YBZZ141)

\section{References}

[1] Nunia. Carbonara Innovation process within geographical clusters: a cognitive Approach [J]. Technovation, 2004. (24):17-28.

[2] Montoro-Sanchez A., Ortiz-de-Urbina-Criado M., Mora-Valentin E. M. Effects of knowledge spillovers on innovation and collaboration in science and technology parks [J]. Journal of Knowledge Management, 2011, 15(6):948-970.

[3] Baptista Rui. Geographical Clusters and Innovation Diffusion [J]. Technological Forecasting and Social Change, 2011, 66(1): 31-46.

[4] HUANG Hai-yang, CHEN Ji-xiang. Games Analysis on the technology innovation Diffusion of University and Enterprises' Innovation Adoption. Scientific Management Research, 2012, 30(6):61-64.

[5] Gao Tao (Tony), Leichter Gordon, Wei Yinghong. Countervailing effects of value and risk perceptions in manufacturers' adoption of expensive, discontinuous innovations [J]. INDUSTRIAL MARKETING MANAGEMENT. 2012, 41(4): 659-668.

[6] Risselada Hans, Verhoef Peter C., Bijmolt Tammo H. A. Dynamic Effects of Social Influence and Direct Marketing on the Adoption of High-Technology Products [J]. JOURNAL OF MARKETING, 2014, 78(2): 52-68.

[7] Wang Zhanzhao; Ma Yonghong; Zhang Fan. Study on Technology Innovation Diffusion Model and Simulation Based on System Dynamics. Science \& Technology Progress and Policy, 2015, 32(19):13-19.

[8] HUANG Wei-qiang; YAO Shuang; ZHUANG Xin-tian; XIN Wei. Innovation Diffusion Modeling Based on Scale-Free Networks. Journal of Northeastern University (Natural Science), 2015, 36(8):1212-1216.

[9] Stummer Christian, Kiesling Elmar, Guenther Markus. Innovation diffusion of repeat purchase products in a competitive market: An agent-based simulation approach [J]. EUROPEAN JOURNAL OF OPERATIONAL RESEARCH. 2015, 245(1): 157-167.

[10] XU Ying-ying; QI Liang-qun. Research on low carbon technological innovation diffusion in enterprises clusters based on evolutionary game theory on complex networks. China Population, Resources and Environment, 2016, 26(8):16-24.

[11] MA Yong-hong, WANG Zhan-zhao, LI Huan, ZHOU Wen. Network Structure, Adopters Preference and Innovation Diffusion: A Simulation Analysis of the S-D Model of Innovation Diffusion Based on the Decision Making Process of Adopters. Operations Research and Management Science, 2016, 25(3): 106-116.

[12] Anand Adarsh, Agarwal Mohini, Aggrawal Deepti. Unified approach for modeling innovation adoption and optimal model selection for the diffusion process [J]. JOURNAL OF ADVANCES IN MANAGEMENT RESEARCH, 2016, 13(2): 154-178.

[13] Merton R C. Option pricing when underlying stock returns discontinuous [J]. Journal of Financial Economic, 1976, 3(1-2): $125-144$.

[14] Jensen R A. Multiplant firms and innovation adoption and diffusion [J]. Southern Economic Journal, 2004, 70(3): 213-229.

[15] Kerr S. On the Folly of Rewarding for A While Hoping for B [J]. Academy of Management Journal, 1975, 18(4):769-783.

[16] Holmstrom B, Milgrom P. Aggregation and Linearity in the Provision of Intertemporal Incentives [J]. Econometrica, 1987, (55): 303-328. 